\title{
Research on Mobile Phone Dependence of College Students in Information Age and Its Countermeasures
}

\author{
Zhenpeng Zhao \\ School of Art and Design \\ Huanghe Science and Technology College \\ Zhengzhou, Henan, China 450006
}

\begin{abstract}
With popularization of mobile phones, the problem of mobile phone dependence among college students is increasingly serious. Mobile phone dependence influences physical and psychological health of college students, increases the family financial burden of college students and causes adverse effects on academic atmosphere of colleges. The reasons are diversified. It needs joint efforts of the society, school, family and students to furthest reduce the harm of mobile phone dependence.
\end{abstract}

Keywords-colleges; college students; mobile phone dependence; countermeasures

\section{INTRODUCTION}

As "the fifth media" after newspaper, radio, television and internet, mobile phone has certain influence on people's life, learning, communication and way of thinking, including positive influence and negative influence. Mobile phone dependence is one of the negative effects of it. This article takes college students as objects of investigation, explores and analyzes current situation, harm, reason and countermeasures of mobile phone dependence.

\section{Characteristics of MobiLe PHONE DePENDENCE OF COLLEGE STUDENTS IN UNIVERSITIES}

The author makes questionnaire survey on 500 college students from three universities in Zhengzhou area, gives out 500 questionnaires and takes back 493, including 485 valid questionnaires and does statistic analysis on these questionnaires. It is found that nearly $70 \%$ of college students have the problem of mobile phone dependence to varying degrees. The excessive dependence of college students on mobile phone shows in the following aspects.

\section{A. Spend Too Much Time in Using Mobile Phone}

According to the survey, $35 \%$ of college students keep their mobile phone in the state of starting up in 24 hours and $65 \%$ of college students spend more than eight hours in using mobile phone every day. They mainly use mobile phones to call, send short message, surf the internet and entertain. $3 \%$ of them spend more than two hours in calling each day; $7 \%$ of them spend more than two hours in sending short messages each day; $45 \%$ of them spend more than two hours in surfing the internet every day and $22 \%$ of them spend more than two hours in listening to music, playing games each day.

\section{B. Problems of Mobile Phone Existence Are Serious}

Mobile phones become the tool for college students to communicate, entertain and study, play the role of daily necessity and become a part of college students' body just as cells and necessary condition of their existence. It shows the state of "Human-Machine Unity". The relationship between college students and mobile phones is possession and dependence of each other, instead of the relationship that mobile phones are decided and used by college students. It makes mobile phone existence become reality. Under this circumstance, college students use mobile phones to replace other functions: Firstly, playing mobile phones replaces other ways of entertainment: some college students are addicted to entertainment on mobile phones, using ways such as play various mobile games and watch video programs to replace other healthy ways of entertainment. Secondly, mobile QQ and Fetion replace interpersonal communication in real life: some college students devote all emotions and energy to instant chat, short message and talking on the phone to seek emotional comfort and neglect face-to-face direct communication between people in real life. Thirdly, they excessively depend on functions of mobile phone and neglect promotion of selfability. Some college students spend a lot of time in searching and collecting information that has no relationship with their work and study or isn't urgently required by them through surfing the internet with mobile phone, which lead to the fact that their work efficiency and learning efficiency reduce.

\section{Psychological Problems of Mobile Phone Dependence Are Obvious}

According to the investigation, when frequently using mobile phones, some college students have appeared some psychological problems. $23 \%$ of college students surveyed think they will have the fidgets without mobile phones. $36 \%$ of them think it is difficult to power off the mobile phone. $37 \%$ of them think they will feel fidget if they forget to carry mobile phone. $10 \%$ of them tell that when the mobile phone of others rings, they will think it is theirs. In real life, some college students will put mobile phone beside them so that they can take it every now and then, even when they are sleeping; they often take out mobile phones to watch unconsciously; when communicating with people, they excessively depend on 
mobile phones. They could have directly communicated with others face-to-face, but they always send short messages or call up. These show that the problem of mobile phone existence among college students has been increasingly serious.

\section{INFLUENCES OF MOBILE PHONE DEPENDENCE ON COLLEGE STUDENTS}

\section{A. Influence Physical and Psychological Health of College Students}

Firstly, electromagnetic wave of mobile phones, fixed body posture and repeated and mechanical movement when using it will cause poor physical fitness; using mobile phones for a long time will lead to unhealthy psychology or behaviors such as loneliness, depression and autism. Secondly, frequently using mobile phones will increase the probability for college students to receive illegal and harmful information, such as flooding of short messages and internet pictures with pornographic contents. It is easy for them to mislead college students, reduce moral level of them and let them lose perfect personality and psychology.

\section{B. Increase Financial Burden of College Students}

With continuous improvement of living standard in society, the consumption level of college students also improves gradually. Mobile phone consumption has become an essential part of college students' daily expenses. Acquisition expenses, call charge, internet access fees and entertainment fees of mobile phones have become important part of their daily consumption. It certainly will bring unnecessary financial burden for students with poor family economic conditions.

\section{Destroy Normal Order of Universities}

Mobile phone dependence of college students seriously destroys normal teaching order of universities. It is mainly reflected in the following aspects: Firstly, some college students have weak self-control ability, play mobile phones in class and kill classroom time through entertainment on mobile phone, which certainly will lead to the situation that students' performance decreases and learning quality declines. Secondly, mobile phones ring in the classroom, which influence normal teaching order and interrupt normal teaching contents of teachers. Thirdly, with popularization of mobile phones among college students, the mobile phones encourage cheating behaviors of college students.

\section{REASONS OF MOBILE PHONE DEPENDENCE AMONG COLLEGE STUDENTS}

\section{A. Factors of Society}

Firstly, it doesn't receive enough attention. At present, the society obviously doesn't pay enough attention to mobile phone dependency of college students, different from the researches on internet addiction at full swing. Although they put forward the worries about influence of rapid development of mobile phones on human and the society, most researches mention the harm did by mobile phone radiation to human body, and misdirection error caused by mobiles phones to planes and steamers. The influence of mobile phones on society and culture rarely attracts the attention of scholars. The problems of mobile phone dependence and excessive dependence of college students are seldom mentioned by the society. People don't pay enough attention to it for a long time. Secondly, it is increasing popularization of mobile phones. As a kind of fashionable, convenient and multipurpose communication tool, mobile phones are popular among college students and become standard facility of them. Students can use it to timely connect with other, relax and extend individuality, but students depend on it, which has negative influences.

\section{B. Factors of Students}

Firstly, college students are eager to acquire information. Because mobile phones have large amount of information and can convey information fast and conveniently, send information whenever and wherever possible, it successfully attracts college students' attention, meets their requirements for information, reduces their mental stress because of lack of information and eliminates uncertainty in environment. Psychological characteristics of young students determine that mobile phones can gain favor of college students. Secondly, college students pursue fashion. For young students keen on fashion, their mental motivation to pursue fashion is to seek common points while reserving difference. To pursue fashion, quite a few students frequently change mobile phones and continuously pursue promotion of model, brand, function, style and price of mobile phones. Thirdly, it is emotional migration of college students. At present, college students often cannot correctly evaluate themselves (overestimation or undervaluation) and make the gap between ideal and reality become big. It is easy to lead to conceited or self-abased psychology of young students, who cannot leisurely meet the challenges of the society. When these complicated feelings accumulate over a long period, college students need to release mental stress and transfer their emotions. At current society, mobile phones cater to mental state of college students with its unique characteristics and become "tips" for them to seek security and dispel depression.

\section{Factors of Universities}

Firstly, the system needs improvement. According to the survey, there isn't system related to use of mobile phones in most universities, only having oral admonishments of instructors or teachers. It leads to the situation that college students take mobile phones in class and it influences teaching efficiency. Secondly, the education isn't sound. At present, universities don't educate college students about how to correctly, reasonably and healthily use mobile phones and related etiquette of using mobile phones. College students are often accustomed to using mobile phones to call up, send short messages and play games in classroom or room for individual study. Most college students think it is universal phenomenon to use mobile phones in class, which shows deficiency in educating students about reasonably using mobile phones and teaching them the etiquette in using mobile phones. Thirdly, the persuasion doesn't have actual effects. In terms of the situation that mobile phone dependence of college students is increasingly serious, leaders and teachers in universities cannot 
take feasible measures, only warning, prohibiting or reminding students. It cannot solve this problem fundamentally. Students still persist their old ways.

\section{Family Factors}

Influenced by long-run exam-oriented education of our country, many parents very strictly discipline their children before they attend university but neglect the education of children after they enter university. They think that there is no need to discipline their children strictly since they have been admitted to university. Under this circumstance, some parents have no idea about school life of their children and only meet the requirements of children randomly. Parents neglect education and indulgently support college students to frequently change mobile phones or carry out mobile phone consumption without limitation. In other words, they play the role of adding fuel to the fire. They promote the possibility of mobile phone dependency of college students.

\section{COUnTERmeasures of Mobile Phone DePENDENCy OF COLLEGE STUDENTS}

\section{A. For Society}

The government shall implement supervision on mobile phone culture through formulating corresponding legal systems, strengthen development and utilization of monitoring technology of mobile phones and appeal to the society to pay close attention to the social issue of mobile phone dependence.

\section{B. For Students}

Firstly, students should develop the ability of moral selfdiscipline. They shall determinedly resist harmful mobile phone culture, strengthen self-improvement, reinforce immunity to unhealthy information in mobile phone culture and become a person truly having good media literacy. Secondly, they should strengthen self-education. College students should make efforts to fully exert subjective initiative with positive attitude, use strong will to resist the temptation of mobile phone culture, strictly standardize the use of mobile phones and improve personal cultivation and moral competence.

\section{For Family}

Parents should put more energy in caring for and helping their children, communicate and exchange with them equally, get to know their inward world as well as guide and educate, supervise them properly by emotionally moving them and enlightening them with reason. Encourage children to spend more time in participating in some healthy activities to let them gain relaxed and pleasant feelings. Besides, they should actively contact with teachers, monitor or classmates of their children, know about learning, life and mental condition of their children to timely assist teachers to correct their unhealthy living habits.

\section{For School}

Firstly, lead and educate college students to correctly use mobile phones. Universities shall improve rules and regulations, strengthen education on students about etiquette in using mobile phones and carry out necessary and effective supervision on college students. Let students realize the significance of using mobile phones appropriately in promoting the formation of good social morality, construction of civilized campus and personality cultivation of college students. Secondly, carry out colorful campus activities. Universities should often organize cultural activities of the campus that have rich and healthy contents and can attract the interest of college students. For example, universities can base on the current situation to carry out pioneering work practice activity of college students, which can not only train good ability of college students but also distract their attention then reduce the possibility of mobile phone dependence. Thirdly, take mobile phone as the platform to implement ideological and political education on college students. Universities shall seize the opportunity to carry out ideological and political work at the new period, take mobile phone as cultural front of ideological and political work at the new period, publicize policies of the Party and our country, campus news and carry out online activities through ways of short message and Fetion to achieve the purpose of implementing ideological and political education on college students.

\section{CONCLUSION}

Mobile phone dependence of college students in class is influenced by themselves, teachers, peer group and recessive school environment. Role determination and role play of themselves, emotional interaction between teachers and students, mutual standardization in peer group and active guidance of teachers for peer group are effective ways to realize classroom teaching in colleges. Good classroom teaching can help students to grow up and become useful person and urge teachers to realize their own value and realize the significance of efficient classroom teaching.

Diversified mobile phone culture has positive influence on ideological and political education of college students on educational pattern and way of thinking. Meanwhile, it also plays a negative role in socialist core values of college students. Universities shall make ideological and political education on college students catch up with rapid development of mobile phone culture, exert positive influence of mobile phone culture, and make efforts to purify harmful mobile phone culture as well as establish healthy atmosphere on campus. At the same time, call on mobile industry to strengthen the construction of healthy mobile phone culture, provide richer competitive products for mobile phone culture with Chinese characteristics and let advanced and mainstream culture lead green and healthy mobile phone culture.

Mobile phone dependence brings huge influences on learning, life and physical and psychological health of college students. The problem of mobile phone dependence generally exists in colleges. Society, universities and families should pay close attention to it and form resultant force to establish good group atmosphere, harmonious campus culture, strengthen humanistic care and psychological counseling and ways for self-education of students, in order to help students to overcome difficulties in mobile phone dependence, develop good volitional quality and then realize healthy development 
both in mind and body. On construction of study style, colleges should educate students to strengthen retraining force for themselves, carry out self-monitoring and reasonably arrange their school life, seize more opportunities to participate in social practice activities, let students integrate in social life, establish good group atmosphere and interpersonal relationship and then study and live healthily and happily. Universities shall actively shoulder the heavy responsibility of active guidance, create good atmosphere for college students to use mobile phones healthily, let them correctly treat mobile phone culture, reasonably use it, develop good habits in using mobile phones and make mobile phone culture in universities develop towards the positive and healthy direction.

\section{REFERENCES}

[1] Tang Rimei, Yang Zhe, Li Kai. Discussion on Influence of Mobile Phone Culture on Ideological and Political Education of College Students and Countermeasures [J], Journal of Shenyang Jianzhu University (Social Science Edition), 2014,v.16; No.5002:196-199.

[2] Tan Liang. Discussion on Influence of Mobile Phone on College Students and Countermeasures [J], Journal of Hunan Financial and Economic College, 2008(5): 140-141.

[3] Pan Liang, Wang Kun, Pang Shulan, Li Kaizhi. Analysis on Current Situation and Countermeasures of Mobile Phone Dependence in College Students [J], China Health Industry, 2015, 36: 41-43.

[4] Zhou Xihua. Exploration on Mobile Phone Addiction among College Students [J], Journal of Chengdu University (Educational Sciences Edition), 2010 (4) : 16-19.

[5] Wu Fang. Research on Mobile Phone Dependence of College Students and Construction of Study Style in Colleges [J], Journal of Xingyi Normal University for Nationalities, 2015,06:107-109. 